\title{
Short-Interfering RNAs as Antivirals Against Rabies
}

\author{
Paulo Eduardo Brandão ${ }^{1}$, Juliana Galera Castilho², Willian Fahl ${ }^{2}$, Pedro Carnieli Jr. ${ }^{2}$, Rafael de Novaes Oliveira ${ }^{2}$, \\ Carla Isabel Macedo', Maria Luiza Carrieri ${ }^{2}$ and Ivanete Kotait ${ }^{2}$ \\ ${ }^{1}$ School of Veterinary Medicine, University of São Paulo; ${ }^{2}$ Pasteur Institute; São Paulo, SP, Brazil
}

\begin{abstract}
This study aimed to test in vitro a RNA-interference based antiviral approach for rabies with short-interfering RNAs (siRNAs) against rabies virus nucleoprotein mRNA. BHK-21 cells were infected with serial dilutions of PV rabies virus strain and transfected with a pool of three siRNAs. Direct immunofluorescence staining showed a 5-time decrease in virus titer when compared to a non-treated plate, showing a promising new approach to the development of antivirals for rabies treatment.
\end{abstract}

Key-Words: siRNA, rabies, antiviral.

Rabies is a fatal encephalitis that affects the Mammalia [1] and human cases of the disease are prevalent mainly in undeveloped countries; affected patients experiment extensive physical suffering. Antivirals currently used against rabies include ketamine, midazolam, ribavirin and amantadine, but only one successful case of human treatment happened in 2004 [2]; furthermore, rabies virus still circumvents most actions aimed to treat and control rabies and to create consensual scientific and political efforts on this area and only very few studies focus on antivirals for this disease.

The RNA interference (RNAi) is based on the ability of double-stranded RNAs, e.g., short-interfering RNAs (siRNAs), to specifically trigger mRNA degradation by the cellular RNAinduced silencing complex (RISC) [3], an ubiquitary cytoplasmatic protein complex that harbors dsRNA-binding domains and an exonuclease domain activated by the first after a dsRNA binds to it [4]. This approach has been successful in in vitro and in vivo assays for Hepatitis $C$ virus [5] and in vitro assays for Dengue virus and HIV [6], but no attempt to apply RNAi against rabies virus infection has been reported so far.

The aim of this study was to test the effect of RNA interference on the decrease of rabies virus titer in vitro.

\section{Materials and Methods}

Three AA(N19)TT siRNAs were designed with antisense strands complementary to rabies virus nucleoprotein $(\mathrm{N})$ mRNA from 221 sequences retrieved from the Genbank (http://www.ncbi.nlm.nih.gov/) aligned by the CLUSTAL/W [7] method with Bioedit 7.0.5.3 [8]: RNA124 (sense 5' GCCUGAGAUUAUCGUGGAG 3'/ antisense 5' AUCCACGAUAAUCUCAGGC 3'),

Received on 16 October 2006; revised 7 March 2007.

Address for correspondence: Prof. Dr. Paulo Eduardo Brandão. Departamento de Medicina Veterinária Preventiva e Saúde Animal, Faculdade de Medicina Veterinária e Zootecnia, Universidade de São Paulo. Avenida Professor Doutor Orlando Marques de Paiva, 87, Cidade Universitária. Zip code: 05508-000. São Paulo, SP, Brazil. Phone: 5511-3091-7655; Fax: 55-11-3091-7928. E-mail: paulo7926@yahoo.com.

The Brazilian Journal of Infectious Diseases 2007;11(2):224-225. (C) 2007 by The Brazilian Journal of Infectious Diseases and Contexto Publishing. All rights reserved.
RNA750(sense5'GCACAGUUGUCACUGCUUC3'/ antisense5'UAAGCAGUGACAACUGUGC 3') and RNAB (sense 5' GACAGCUGUUCCUCACUCG 3'/ antisense 5' AGAGUGAGGAACAGCUGUC 3'), targeting the regions starting at positions 123, 749 and 903 of rabies virus nucleoprotein gene, respectively, in an area that codes for a highly functional constrained portion of $\mathrm{N}$ protein, which plays a major role in nucleocapsid assembly [9].

All three siRNAs were submitted to BLAST/n at http:// www.ncbi.nlm.nih.gov/BLAST/ and no significant non-N gene homology was found. As the secondary structure of a given RNA is a key feature to the effectiveness of RNAi [10], the secondary structure of the target mRNA was evaluated at 35, 37, 39 and $42{ }^{\circ} \mathrm{C}$ with RNADraw v 1.1 (Mazura Multimedia, Dalagatan 9C:320, 11324 Stockholm, Sweden), based on a broad range of body temperatures that a normal person and a rabid patient can experience [11]. No alteration was found to siRNAs 750 and B; regarding siRNA 124, minor secondary structure instability of the target site was found at the described temperatures.

BHK-21 cells grown in MEM/ $5 \%$ fetal bovine sera (FBS) in 24-well plates at $37^{\circ} \mathrm{C}$ with $5 \% \mathrm{CO}_{2}$ for 48 hours were inoculated with the Pasteur virus (PV) rabies reference strain diluted 10-fold in FBS-free MEM and incubated for two hours at $37^{\circ}$ with $5 \% \mathrm{CO}_{2}$ in a volume of $500 \mu \mathrm{L} /$ dilution. Next, the monolayers were transfected with a pool containing 20 pmols of each of the three siRNA in DEPC-treated water with Lipofectamine 2000 (Invitrogen $^{\mathrm{TM}}$, Carlsbad, CA, USA). A control plate was made with the same virus dilution, but no siRNA was added. Further negative controls included wells inoculated with $100 \mu \mathrm{L}$ Lipofectamine 2000 and DEPC-treated water.

Twenty-two hours post-inoculation, both the control and the siRNA-treated plates were tested by direct fluorescent antibody test (DFA) with anti-rabies virus nucleocapsid antibody conjugated with fluorescein isothiocianate (Biorad Laboratories $^{\mathrm{TM}}$, Hercules, CA, USA) and observed with an epifluorescence microscope. Virus titers were calculated by the Reed-Müench method and fluorescence intensity was quantified as +1 (at least one fluorescent focus in the well), +2 (about $50 \%$ of the monolayers with fluorescence), +3 (about $75 \%$ of the monolayers with fluorescence) and +4 (coalescently fluorescent monolayers). 


\section{Results}

The titer of the PV strain in the control plate was $10^{4,375} \mathrm{TCID}_{50} / 500 \mu \mathrm{L}$ while, in the siRNA-treated plate, the titer fell to $10^{3,625} \mathrm{TCID}_{50}$, about 5 times lower. Fluorescence intensity in the control plate varied from +3 to +4 in $10^{-2}$ to +1 in $10^{-4}$ and fell to +2 in $10^{-2}$ dilution and to +1 in $10^{-3}$ dilution on the siRNA-treated plate. No cytotoxic or cytopathic effect was observed in the monolayers inoculated with Lipofectamine 2000 or DEPCtreated water.

\section{Conclusion}

We conclude that the pool of siRNAs used herein was able to significantly inhibit rabies virus replication in vitro, with no cell damage as depicted from the negative controls and it shows that RNAi can be seen as a promising new approach to the development of antivirals for rabies treatment.

\section{References}

1. Jackson A.C., Wunner W.H. Rabies. San Diego, USA: Academic Press, 2002.
2. Willoughby R.E. Jr., et al. Survival after treatment of rabies with induction of coma. N Engl J Med 2005;352:2508-14.

3. Dykxhoorn D.M., Novina C.D., Sharp P.A. Killing the messenger: short RNAs that silence gene expression. Nat Rev Mol Cell Biol 2003;4:457-67.

4. Agrawal N., et al. RNA interference: biology, mechanism, and applications. Microbiol Mol Biol Rev 2003;67:657-85.

5. Wang Q.C., Nie Q.H., Feng Z.H. RNA interference: antiviral weapon and beyond. World J Gastroenterol 2003;9:1657-61.

6. Tan F.L., Yin J.Q. RNAi, a new therapeutic strategy against viral infection. Cell Res 2004;14:460-6.

7. Thompson J.D., Higgins D.G., Gibson T.J. CLUSTAL W: improving the sensitivity of progressive multiple sequence alignment through sequence weighting, position-specific gap penalties and weight matrix choice. Nucleic Acids Res 1994;22:4673-80.

8. Hall T.A. BioEdit: a user-friendly biological sequence alignment editor and analysis program for Windows 95/98/NT. Nucl Acids Symp Ser 1999;41:95-8.

9. Kouznetzoff A., Buckle M., Tordo N. Identification of a region of the rabies virus $\mathrm{N}$ protein involved in direct binding to the viral RNA. J Gen Virol 1998;79:1005-13.

10. Ui-Tei K., et al. Guidelines for the selection of highly effective siRNA sequences for mammalian and chick RNA interference. Nucleic Acids Res 2004;32:936-48.

11. Burton E.C., et al. Rabies encephalomyelitis: clinical, neuroradiological, and pathological findings in 4 transplant recipients. Arch Neurol 2005;62:873-82. 